\title{
O TECIDO EMPRESARIAL CONIMBRICENSE (1928-1936) SUBSÍDIOS PARA O SEU ESTUDO*
}

\author{
Valentino José C. do Vale Alves*"
}

\begin{abstract}
A estrutura empresarial conimbricense, entre os anos de 1928 e 1936, era constituída por uma heterogeneidade de actividades industriais $e$ comerciais, o que atesta a vocação "ecléctica" da cidade, destacando-se, no entanto, o ramo ligado à alimentação e bebidas. Neste período assistiu-se a um desenvolvimento da região que acarretou a transformação das empresas que, gradualmente, adoptaram formas societárias mais modernas. Procurava optimizar-se as respostas num mercado em crescimento, mas que também, cada vez mais, sofria a concorrência de produtos de fora da região e do país sendo, portanto, mais influenciável a partir do exterior.
\end{abstract}

\section{INTRODUÇÃO}

O trabalho agora apresentado tem um objectivo preciso e delimitado: contribuir para o conhecimento da estrutura empresarial conimbricense entre os anos de 1928 e 1936.

Em termos espaciais estamos perante uma região que ultrapassa os limites urbanos da cidade de Coimbra. Encontramo-nos, mais propriamente, na zona de influência de Coimbra, tendo a cidade como fulcro ou ponto central ${ }^{1}$. O raio de acção de uma cidade abrange a distância económica de trinta quilómetros, enquanto que o limiar da procura se situa a dez quilómetros ${ }^{2}$.

\footnotetext{
${ }^{* *}$ Professor do Ensino Secundário; Licenciado em História.
} 
No entanto, no que diz respeito à vida económica de Coimbra, esse raio de acção terá forçosamente que ser alargado, uma vez que as relações entre esta cidade e a Figueira da Foz eram importantíssimas ${ }^{3}$. Assim, decidi optar pelo alargamento da área de estudo a localidades como Montemor-o-Velho, Penacova, Lousã, Miranda do Corvo, S. Martinho da Cortiça, Mortágua e Condeixa-a-Nova e, não obstante não se poder investigar mais minuciosamente os seus casos, considerei que os dados recolhidos eram transmissores de informação passível de auxiliar nesta investigação.

Pelo que atrás fica dito, depreende-se que, quando se utílizar a designação de Coimbra, se pretende indicar a área citadina propriamente dita e os espaços económicos que se encontram sob o seu raio de acção.

Clarificados os limites espaciais convém abordar o intervalo temporal. A escolha dos anos de estudo, compreendidos entre 1928 e 1936, não foram fruto do acaso. Decidi optar por esta nesga temporal porque se abria a possibilidade (se bem que difícil) de observar os reflexos da crise de 29 na economia de Coimbra. Por outro lado, se oito anos - período relativamente curto - não permitem ter uma visão evolutiva precisa, porque limitada, da realidade empresarial, mormente da constituição e dissolução de sociedades, consegue-se, não obstante, ter uma perspectiva evolutiva de curto prazo.

No que diz respeito ao objectivo primordial deste trabalho, este divide-se em duas partes: por um lado, dar algumas achegas para o conhecimento da mortalidade e natalidade das empresas de Coimbra, realçando os ramos e sociedades que mais se destacavam, bem como analisar o seu capital social; por outro lado, estudar o crédito privado industrial.

É evidente que, pela extensão da informação disponível e pela profundidade da investigação, exigindo um estudo pormenorizado, optámos por concentrar a nossa atenção no sector industrial, sem perder de vista, no entanto, o sector comercial, que nos permite, por comparação, delinear melhor a realidade da vida económica conimbricense.

Quanto às fontes manuscritas utilizadas, limitámo-nos aos Livros Notariais $^{4}$ que se encontram no Arquivo da Universidade de Coimbra, o que acaba por ser lacunar, uma vez que, embora não seja habitual, uma sociedade com sede em Coimbra pode ser constituída num outro local. Porém, contra esta adversidade era praticamente impossível lutar.

Quase não é preciso sublinhar a riqueza da informação contida nesta documentação notarial, "que nos permite reconstruir a vida económica ao seu nível mais concreto"; diremos mesmo que, através dela, se sente todo o palpitar da vida económica e social; porém, acaba por ser específica, obrigando a um complemento de investigação, difícil de efectuar, tal é a limitação de tempo para efectuar este trabalho. 
Assim, é minha intenção, mais do que aprofundar o estudo deste tema, tentar abrir perspectivas, dando hipóteses para futuros trabalhos de investigação.

Mas foi a partir das qualidades e limites das fontes utilizadas que alicercei o meu trabalho, como foi ciente das limitações temporais que o aceitei fazer.

\section{I - AS SOCIEDADES CONIMBRICENSES (1928-1936)}

\section{ALIMENTAÇÃO E BEBIDAS}

Entre 1928 e 1936, na zona de Coimbra, o mais empreendedor dos ramos foi o concernente à alimentação e bebidas, tendo-se então constituído 60 empresas, das quais 26 eram industriais e as restantes 34 comerciais, o que equivale a uma média de mais de sete constituições por ano.

Embora a quantidade de empresas comerciais criadas tenha sido superior às industriais, no que diz respeito ao capital social envolvido, neste sector a média envolvida elevava-se aos $68500 \$ 00$, enquanto que no comércio tal valor descia para os $24800 \$ 00$ por firma. Como seria de esperar, o apetrechamento técnico necessário para fazer mover uma empresa industrial obrigava a maiores investimentos que no comércio.

Neste período foi frequente assistir-se à constituição de sociedades que se dedicavam à exploração comercial de mercearias e de restaurantes e/ou cafés, sociedades estas que respondiam ao crescimento do mercado conimbricense e cuja profusão era facilitada pela "mediana" quantidade de capital exigido neste tipo de investimentos. Excepção feita à sociedade que girava sob a designação de Manuel Serrão \& Companhia, constituída a 28 de Fevereiro de 1928, com 180 mil escudos de capital social.

Das sociedades comerciais já focadas, vieram a falir uma mercearia e dois cafés e/ou restaurantes, constituindo a firma Loureiro \& Companhia um caso de fracasso, uma vez que os sócios dissolveram a sociedade um mês após a sua constituição.

No sector industrial não se pode deixar de destacar a panificação ${ }^{6}$ que, apesar de, em algumas zonas, ser ainda então uma actividade virada para o auto-abastecimento, surge neste período com onze empresas constituídas e com notável sucesso económico, pois apenas a firma Adelino Baêtas \& Companhia, constituída em Outubro de 1933, viria a falir em 1935.

Não se pode focar neste estudo todas as empresas, aliás nem é esse o nosso objectivo. Iremos, no entanto, apontar alguns casos de realce, mormente aqueles em que temos conhecimento da data da sua constituição e respectiva falência: 
1) A constituição da Empresa de Pesca São Jacinto, Ld. ${ }^{\text {, }}$, dedicada à pesca do bacalhau, constituída em Julho de 1936, com sede em Coimbra, com o avultado capital social de 400 mil escudos.

2) A instalação de duas indústrias de massas alimentícias de diferentes dimensões: por um lado, a fábrica José B. Miranda, Ld. ${ }^{a}$, constituída com o capital social de 350 mil escudos; e, por outro, a fábrica de Joaquim Botelho Miranda, Ld. ${ }^{\text {a }}$, com apenas 80 mil escudos de capital ${ }^{7}$.

3) Em Fevereiro de 1931 constituiu-se a Sociedade de Lacticínios de Taveiro, Ld. ..; que viria a falir 5 meses depois.

4) A empresa Marques \& Santos, constituída em Março de 1932, destinada a explorar o comércio de retalho de vinho e seus derivados, faliu em 1935.

5) No período em estudo, faliram duas empresas dedicadas à indústria da moagem. Foi o caso da sociedade Póvoa e Filho que, desde 1920, se dedicava a este negócio e veio a falir em 1928; e a empresa Amaral e Marrano, Ld. a , também constituída em 1920, que veio a falir em 1934.

Em conclusão: $O$ ramo da alimentação e bebidas teve um crescimento considerável durante este período, na região de Coimbra, sendo diversificado o tipo de sociedades comerciais e industriais então constituídas.

\section{CALÇADO, TÊXTIL E VESTUÁRIO}

No ramo que diz respeito ao calçado, têxtil e vestuário, o sector comercial sofreu um crescimento maior do que o da indústria, sobretudo devido ao nascimento de grande número de sociedades de exploração do comércio de tecidos e fazendas, destacando-se, de entre este tipo de estabelecimentos, a empresa constituída em Maio de 1929, que girava sob a designação de Lagos \& Irmão, constituída com o capital social de 300 contos.

No que diz respeito ao capital social deste ramo, a sua média rondava os 59 contos por empresa, para a indústria, e os 67 contos para o comércio; mas esta, como média que é, escamoteia um pouco a realidade, uma vez que as clivagens de capital social adentro de cada sector são enormes. Assim, enquanto a fábrica de chapéus A. F. de Brito, Sucessores, Ld. ${ }^{\text {, }}$, foi constituída em 1934 com a quantia de 10 contos, a Empresa Fabril de Malhas, Ld. a , nesse mesmo ano, foi constituída com a generosa quantia de 500 contos; por outro lado, no sector comercial, no pólo contrário ao da referida empresa Lagos \& Irmão, encontramos várias sociedades constituídas com o capital social de 10 contos. Todos estes indicadores parecem comprovar a existência de uma grande diversidade na dimensão das sociedades, adentro de um mesmo sector ou de um mesmo ramo de 
actividade. No entanto, realça-se a tendência para o aumento da dimensão das sociedades, muitas vezes fruto do aumento do número de sócios.

Uma empresa deveras conhecida ainda hoje, em Coimbra, sofreu durante esta nesga temporal um período algo conturbado. Falamos da Turíbio de Matos \& Companhia que, constituída em 1923 para se dedicar ao comércio de solas e cabedais, foi dissolvida em 1928, sendo constituída nova sociedade que, logo depois, voltou a dar lugar ao primitivo conjunto de sócios.

Em suma: assiste-se entre 1928-1936 à dissolução de onze empresas, o que, tendo em conta o número de novas sociedades (32), revela ter sido considerável o crescimento efectivo deste ramo. Para ajudar à caracterização deste ramo convém salientar a diversidade de actividades comerciais e industriais existentes, que iam desde as lojas de tecidos, fazendas ou malhas, às camisarias e retrosarias, entre outras, até às fábricas de calçado e de lanifícios, às chapelarias ou alfaiatarias.

Tratava-se, portanto, de um ramo de actividade em plena expansão e que teve, no ano de 1928 , o seu auge no que diz respeito à constituição de novas empresas.

\section{MADEIRA, PAPEL E ARTES GRÁFICAS}

Das sociedades constituídas entre 1928 e 1936, em Coimbra, pertencentes ao ramo da madeira, dez dedicavam-se à indústria, sendo somente uma do tipo estritamente comercial, pois sabe-se que muitas marcenarias e pequenas fábricas de móveis acumulavam a dupla função de transformar e vender ao público. Mais concretamente, tratava-se de uma papelaria-tabacaria, constituída em Setembro de 1930, sob a designação de Silva Raposo \& Companhia, Ld. $\stackrel{\text {. }}{\text {. }}$

Adentro das sociedades industriais destacam-se as que trabalhavam a madeira, sobretudo marcenarias, serrações e carpintarias. De entre estas sobressai a firma Caseiro \& Rama, Ld. ${ }^{\text {a }}$, com sede em Pombal, nascida em 1934 com o avultado capital social de 120 contos, mas que havia de falir passados quatro meses.

Sabendo-se que o fabrico do papel é um dos de maior tradição na área de Coimbra $^{8}$, a constituição, em 1930, de uma empresa de dimensão assinalável parece ser apenas uma continuação dessa tradição. Foi assim que surgiu a

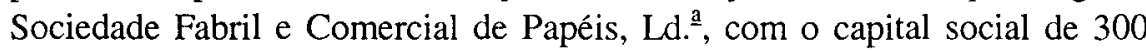
contos, dedicada ao fabrico e venda de papéis de várias qualidades. 
No que diz respeito às artes gráficas, arte com mais de cinco séculos e meio de tradição na área de Coimbra, ${ }^{9}$ assinala-se a constituição de duas tipografias, uma das quais, a firma Pais Martins \& Companhia, surgida em Dezembro de 1935, viria a falir em Junho de 1936.

O fabrico de palitos, sendo uma actividade importante dos arredores de Lorvão, só tardiamente chega a Coimbra, com a fundação, em 1925, da Empresa Mecânica de Palitos, Ld. ${ }^{\text {a }}$, que viria a falir, prematuramente, meses depois da sua constituição ${ }^{10}$.

Todavia, as nossas fontes revelam a existência de uma firma com a mesma denominação cuja constituição data de 1921, com o capital social de 8 contos, vindo a falir a 7 de Março de 1929. Se se trata de outra empresa com a mesma designação, se é a mesma empresa ou se, porventura, o notário registou erradamente a data de fundação, é tarefa para uma futura e mais aprofundada investigação.

Ao serem dissolvidas nove sociedades e sabendo-se que haviam sido criadas onze novas empresas, conclui-se a existência de um fraco crescimento. Mas, no que diz respeito às sociedades industriais, tal crescimento foi da ordem dos $50 \%$, uma vez que às cinco empresas dissolvidas acresce-se dez novas sociedades.

\section{SUBSIDIÁRIAS DA CONSTRUÇÃO E METALURGIA}

O ramo concernente às actividades subsidiárias da construção e metalurgia foi o que menos empresas viu nascer em Coimbra, durante o período em estudo, contando com apenas oito, a saber: duas fundições e uma metalurgia, duas construtoras civis e três dedicadas ao fabrico de cerâmica de construção.

No que diz respeito ao capital social, a média deste ramo situa-se nos 117 contos por empresa, aparecendo, com capitais claramente acima da média, as duas empresas de construção civil: a Sociedade de Construções e Melhoramentos e o Grupo Construtor de Casas Económicas de Coimbra, com 185 contos e 220 contos de capital social, respectivamente. No entanto, esta última sociedade, criada em Setembro de 1932, haveria de falir em Outubro de 1933.

Aliás, o problema do alojamento era à época altamente discutido, tal era a regularidade com que o assunto era tratado no jornal. Assim, a "casa económica portuguesa" parecia ser a solução para os mais desfavorecidos terem direito a habitação própria, contribuindo-se também para o 
desenvolvimento do país e, sobretudo da indústria, uma vez que "será construída com mão-de-obra e materiais nacionais" $"$.

A sociedade Ignácio, Franco \& Companhia, Ld. ${ }^{\mathrm{a}}$, fundada com o elevado capital social de 185 contos e dedicada ao fabrico e comércio de mosaicos, merece também um destaque.

No que diz respeito às dissoluções, constatámos (para além da já citada atrás) o desaparecimento da sociedade Matos \& Rodrigues, dedicada ao trabalho em mármore e fabrico de cantarias, desde 1922, e da metalurgia Brinca \& Esteves, Ld. $\stackrel{\text {. }}{ }$

Deixámos para o final o caso da Barbosa Coimbra Ribeiro \& Companhia, Ld.. , empresa situada em Taveiro e que se dedicava ao fabrico de cerâmica de construção, com especial relevo para os tijolos e telhas. Esta fábrica, a laborar desde 1931, nasceu de uma sociedade constituída com o capital social de $93922 \$ 00$. Porém, logo a 5 de Fevereiro de 1932 a sociedade foi dissolvida, nascendo nesse mesmo dia uma nova sociedade com a designação de Barbosa \& Ribeiro, Companhia, Ld.. . O estranho desta operação reside no facto da sua segunda constituição ser efectuada com o capital de $3750 \$ 00$.

Como facto mais saliente, destaca-se o avultado capital necessário para fazer movimentar uma indústria deste ramo (dizemos indústria, porque neste período não deparámos com a fundação de qualquer sociedade estritamente comercial), o que explicará o facto de ser o menos representado no que diz respeito ao número de constituições.

\section{OUTRAS ACTIVIDADES}

A existência de uma diversidade de actividades industriais e comerciais em Coimbra, não passíveis de serem enquadradas nos ramos atrás estudados, obrigou à criação de um conjunto suplementar onde se agrupassem.

As sociedades destinadas à exploração de comissões e consignações de produtos foram as que surgiram em maior número. $\mathrm{O}$ facto de grande parte destas empresas serem fundadas, com um baixo capital social, ajuda a compreender a sua proliferação. Estas sociedades de compra e distribuição, acrescida de uma taxa sobre o valor do produto, parecem ter tido um relativo sucesso económico, uma vez que durante o período em estudo não se observou qualquer dissolução.

O desenvolvimento da medicina criou a necessidade do uso de fármacos, o que, por sua vez, obrigou à instalação de farmácias em muitas localidades. Em Coimbra, a carência deste tipo de estabelecimentos era grande uma vez 
que, em apenas oito anos, se observou a criação de dez novas destas empresas.

O nascimento de sete explorações agrícolas e/ou pecuárias atesta, por um lado, a componente rural de Coimbra mas, por outro lado, demonstra a especialização de tais explorações em unidades viradas para o comércio.

A faceta mais urbana de Coimbra surge com a fundação de várias casas ligadas a espectáculos (de massas, alguns, como era o caso do cinema), envolvendo grandes quantidades de capital. Destacou-se a empresa Coimbra

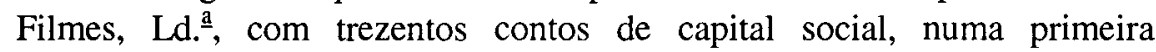
sociedade, que havia de ser desfeita para, em 1931, surgir com uns exorbitantes dois mil contos e uma grande quantidade de sócios. Esta empresa, que actuava como distribuidora, possuindo "um grande stock de belos filmes mudos e sonoros" e como produtora de filmes, publicitando a região, "propagandeando a imagem de Coimbra por todo o país", era uma das mais importantes da cidade ${ }^{12}$.

Duas actividades que surgiram com algum relevo foram, por um lado, as barbearias (muitas delas a acumularem essa função com a de perfumaria) e, por outro, as companhias de transporte, que respondiam à crescentes necessidades de deslocação, entre a cidade de Coimbra e os arredores ou entre Coimbra e outras cidades do país. Salientou-se a empresa José Maria dos Santos \& Companhia, Ld. , criada em 1928, com 120 contos de capital social.

$\mathrm{O}$ aumento da população de Coimbra era uma realidade ${ }^{13}$; "a circulação e o trânsito recrudesceram ininterruptamente e a importância comercial e

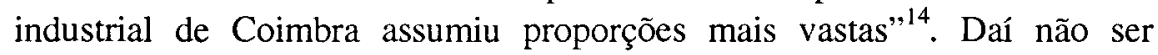
estranho que, em 1933, a Empresa Automobilística da Beira publicitasse que realizava uma carreira diária entre Coimbra e S. Romão ${ }^{15}$, para, em 1938, publicitar viagens diárias entre Coimbra e Porto, Leiria, Lagos da Beira e s. Romão. $^{16}$

Directamente relacionadas com a actividade dos transportes surgem as empresas ligadas ao ramo automóvel, como sejam as oficinas e os stands de vendas. Nesta época, de entre os mais prestigiados stands de vendas surgia o Stand Mondego, Ld. a, representante dos pneus Kelly e dos automóveis e camionetes Chevrolet ${ }^{17}$; e o Stand Pestana \& Companhia, com sede na rua da Sofia, o qual, fruto de ser o representante da Fiat em Coimbra, mereceu uma abertura ao público com a presença de altas figuras da sociedade conimbricense ${ }^{18}$.

Muitas outras actividades proliferaram em Coimbra, como que a rematar a ideia de Falcão Machado que, ao dizer que a cidade tinha "uma importância comercial e industrial extraordinária [...] acrescentava: "não que seja Coimbra uma cidade situada numa região privilegiada, com uma cultura 
especializada ou um produto afamado, com uma indústria característica"19, concluindo que é no eclectismo que a cidade se destaca.

\section{II - AS EMPRESAS E O CRÉDITO PRIVADO}

\section{A EVOLUÇÃO DA EMPRESA}

Da necessidade de optimizar a estrutura empresarial, de modo a acompanhar a transição da economia da fase pré-capitalista para a fase capitalista $^{20}$, advém o processo de transformação das empresas de formas societárias pouco evoluídas para formas mais modernas. Neste âmbito, desde cedo o estado português legislou neste sentido, regulando a constituição de sociedades em nome colectivo, em comandita, anónimas e por quotas ${ }^{21}$.

No seguimento das alterações jurídicas, só lentamente se concretizaram as respectivas mudanças práticas, mormente a partir dos anos 20 do nosso século. Esta pesquisa, ao focar desde os anos terminais da década de vinte aos meados dos anos trinta, pode dar pistas quanto ao rumo tomado por este processo.

De todas as empresas industriais constituídas, na zona de Coimbra, nenhuma adquiriu a forma de sociedade anónima ou em comandita. Ao invés, a maioria formou-se como sociedade por quotas (57\%), ficando as sociedades em nome colectivo com $39 \%{ }^{22}$.

Mas, talvez mais relevante que esta constatação é o facto, de entre 1932 e 1936, das 44 empresas constituídas apenas dez são em nome colectivo, quatro civis particulares e as restantes quotizadas. Provando que aquelas sociedades, de "colaboração entre indivíduos com distintos graus de aptidão" ou de cariz "dinástico", estavam em franco declínio. Pelo contrário, as sociedades por quotas passam a ter uma função cada vez mais relevante, surgindo tanto nos ramos progressivos como nas actividades tradicionais ${ }^{23}$, sobretudo devido às crescentes necessidades de capital e à multiplicação de investimentos feitos por um só empresário.

No sector comercial a distribuição era análoga, com $44 \%$ das sociedades a constituírem-se em nome colectivo, 55\% por quotas e apenas 1 sociedade civil particular. 


\section{NATALIDADE E MORTALIDADE EMPRESARIAL}

Depois de ficar demonstrado o ganho de relevância das sociedades quotizadas na zona de Coimbra, convém traçar a linha evolutiva da constituição e dissolução de empresas industriais e comerciais, no intuito de discernir se o período em estudo foi de crescimento empresarial ou não.

Antes de passar à análise dos dados recolhidos, convém deixar uma breve explicação teórica. Assim, se um elevado número de empresas constituídas representa, em princípio, que uma dada economia se encontra em crescimento, o oposto se passa em relação às dissoluções. Será então, pela diferença entre estas duas realidades que se avaliará melhor a real evolução empresarial dessa economia.

No entanto, há que deixar duas ressalvas: primeiro, uma economia não pode ser compreendida somente a partir destas variáveis; segundo, a constituição e, sobretudo, a dissolução de sociedades não implica obrigatoriamente $o$ funcionamento ou encerramento efectivo da correspondente unidade industrial ou comercial.

Conscientes das limitações atrás referidas, ao interpretarmos o gráfico I, verificamos que o crescimento real das sociedades industriais e comerciais de Coimbra foi sensível à turbulência económica deste período, verificando-se que: a) 1929 e 1930 foram os anos onde o crescimento efectivo foi mais acentuado; b) 1931 correspondeu a um ano de crise ${ }^{24}$ fruto, sobretudo, do elevado número de dissoluções; c) após esta quebra em 1931, de 1932 a 1936, assiste-se a uma gradual tendência de crescimento, que nem o ligeiro declive no ano de 1934 chega para pôr em causa. 


\section{Gráfico I \\ CONSTITUIÇÃO E DISSOLUÇÃO DE SOCIEDADES EM COIMBRA} (1928-1936)

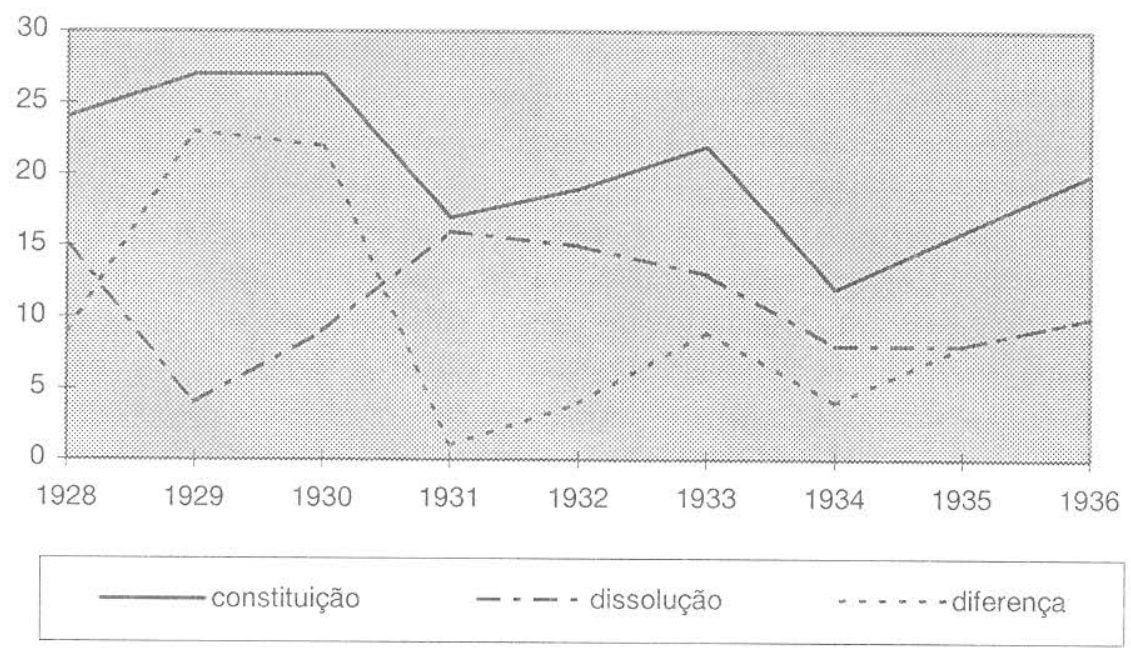

Em suma: mais do que as variações no quantitativo de sociedades criadas, esta época ficou marcada pelas bruscas variações nas dissoluções, o que parece indicar que existia um número mais ou menos estável de empresários decididos a arriscar no comércio ou na indústria. Mas, por outro lado, também houve anos em que a mortalidade das sociedades foi elevada, com prejuízos para o tecido empresarial conimbricense e para a economia da cidade.

\section{O CAPITAL SOCIAL}

Já abordámos no capítulo anterior o capital social de algumas empresas, o que nos permitiu indiciar a sua real dimensão, embora conclusões mais seguras obrigassem a um estudo minucioso.

Pese, embora, a análise do capital social implicar a distinção entre capital fixo e circulante, as limitações impostas pela documentação utilizada veda-nos a possibilidade desse estudo. Todavia, deixamos algumas conclusões retiradas a partir dos dados observados: 
a) a constituição de empresas no sector comercial exige, por norma, menores quantidades de capital do que no sector industrial;

b) o ramo $\mathrm{D}$, e no que se refere ao sector industrial, é o que exige uma maior quantidade de capital (uma média de $127000 \$ 00$ por empresa). No sector comercial, destaca-se, pela mesma razão, o ramo B - com uma média de $67000 \$ 00$ por empresa;

c) no ano de 1929 , atingiram-se os maiores valores de capital social, ascendendo o total a $2454 \$ 00$, sendo a média por empresa de $90000 \$ 00$;

d) foi no ramo A que mais se investiu, sendo o total de $1782 \$ 00$ para a indústria e $845000 \$ 00$ para o comércio.

\section{O CRÉDITO PRIVADO}

O crédito é um dos indicadores do estado de uma economia, ${ }^{25}$ logo um precioso auxiliar no estudo dos sectores económicos ${ }^{26}$.

Pode pensar-se no crédito como uma troca. Porém, ao acrescentar-se o factor tempo ${ }^{27}$ e o elemento psicológico da confiançaa ${ }^{28}$, marca-se-lhe uma feição específica. Assim, embora no plano teórico o crédito não apresente para o credor os riscos de um investimento - industrial, comercial ou outro não deixa de obrigar a uma renúncia temporária da posse e gestão directa do capital. Ora, tal alienação do capital só é economicamente justificável, desde que o credor espere que o capital cedido se multiplique, através do juro a pagar conjuntamente com a contraprestação ${ }^{29}$.

Neste âmbito, as ligações entre o crédito e a indústria são óbvias, pois as avultadas quantidades de capital exigidas pala crescente complexificação daquele sector obriga, frequentemente, a recorrer ao empréstimo ${ }^{30}$.

Para Portugal, apesar de não estar suficientemente estudada a conexão entre a nossa incipiente industrialização e o binómio capital/crédito ${ }^{31}$, parece indiscutível que nem um nem outro pareciam muito inclinados em cooperar com o sector industrial ${ }^{32}$. Se tal conclusão é aplicável ao país, também o será para a área de Coimbra, entre 1867 e $1927^{33}$. Veremos se o será para a cidade de Coimbra e zona de influência, entre 1928 e 1936.

Não obstante o crédito privado e público não poderem ser dissociados, no âmbito da nossa investigação apenas focaremos o crédito privado industrial embora o comercial também seja focado, de molde a que a perspectiva seja mais abrangente -, ou seja, "aquele cujo receptor (devedor) é uma entidade privada, seja um artesão, um industrial ou uma empresa dedicada à indústria" ${ }^{34}$. Dentro do crédito privado industrial limitar-me-ei ao não bancário ou irregular. 
Entre meados do século XIX e 1902, no centro urbano de Coimbra, o crédito industrial ocupava um lugar de destaque, comparativamente com o crédito comercial e agrícola. Por outro lado, os artesãos recorriam mais ao crédito do que o concediam, ${ }^{35}$ o que contrastava com os negociantes que, imbuídos de um espírito capitalista, viam no crédito (concedido) um meio de obtenção de lucro ${ }^{36}$.

Para o intervalo temporal de 1928-1936, e a partir da análise das quitações $^{37}$, verifica-se que o crédito industrial apresenta uma notória inferioridade comparativamente ao crédito comercial $^{38}$. A diferença materializa-se no número de operações de crédito, sendo de 12 as relativas ao industrial e de 22 as referentes ao comércio. Por outro lado, no que diz respeito ao capital utilizado, o crédito comercial atinge os $11349000 \$ 00$, enquanto o industrial fica pelos $421000 \$ 00$.

Em suma, comprova-se que, em Coimbra, o crédito industrial surge em posição secundária relativamente ao crédito comercial, o que, como se disse atrás, já era uma tradição.

Mas, o crédito industrial tem para os devedores uma função diferente, consoante a dimensão do próprio agente:

a) Nas grandes empresas - As operações de crédito permitem injecções de capital, levando à sua modernização e dinamização ${ }^{39}$. Em Coimbra, os agentes industriais somente uma vez foram devedores de montantes muito elevados. Tratou-se da Fábrica de Cal de Coimbra, que conseguiu amortizar completamente a dívida de $175000 \$ 00$ ao proprietário José dos Santos.

b) Nos empresários em nome individual - Ao invés, eram devedores de pequenas importâncias que nunca ultrapassaram as duas dezenas de escudos, destinando-se este pequeno crédito a fazer face a carências imediatas ${ }^{40}$.

\section{O ESTATUTO SOCIOPROFISSIONAL DE CREDORES E DEVEDORES}

Considerou-se escusado, porque evidente, que a observação das categorias socioprofissionais, considerando o crédito industrial e comercial, resultaria numa superioridade dos indivíduos e empresas ligadas a este último sector. Tendo em conta que o objectivo primordial do nosso trabalho é a análise da estrutura empresarial partindo do sector industrial, só tangencialmente - e de molde a melhor compreender a realidade sobre a qual nos debruçamos - temos abordado o sector comercial. Assim, neste 
subcapítulo, analisarei as quitações onde os intervenientes (credores ou devedores) pertençam ao sector industrial. É a partir desta perspectiva que, de seguida, abordaremos as categorias socioprofissionais dos intervenientes nas operações de crédito industrial.

Ao analisar o grupo dos credores $^{41}$, desde logo se realça o facto de os industriais aparecerem como o estrato mais representado, secundados pelos proprietários e sociedades industriais. Por seu turno, os artesãos correspondem, em termos individuais, a uma ínfima percentagem e, mesmo quando agrupados, não ultrapassam os $15 \%$. Isso parece indiciar a fraca disponibilidade de capital deste grupo para empréstimos, comprovada pelos baixos montantes envolvidos ${ }^{42}$.

Ao perspectivar a análise da globalidade dos credores - mormente se tivermos em atenção o crédito industrial e comercial -, constatamos que a variedade é uma constante neste tipo de operações, compreendendo desde indivíduos ligados a profissões mecânicas, até negociantes, comerciantes, proprietários ou sociedades ${ }^{43}$, acrescentando-se a este vasto leque um oficial do exército.

Parecem provadas, mais uma vez, as dificuldades na obtenção de financiamento sentidas pelos agentes industriais, a partir da oferta bancária, obrigando a uma procura junto de privados que vêem nestas operações um meio de rendibilizar o seu capital.

Adentro do grupo dos devedores ${ }^{44}$, os proprietários surgem como o estrato social mais representado, o que decerto está relacionado com o facto de possuírem bens potencialmente capazes de colmatar a dívida contraída.

O segundo estrato socioprofissional a distinguir-se quantitativamente é o dos artesãos, reflexo das dificuldades financeiras por que passavam algumas actividades tradicionais ${ }^{45}$. Mas, ao verificarmos que as dívidas contraídas correspondiam apenas a $13 \%$, parece demonstrado o gradual desaparecimento destes "artistas" da cena económica de Coimbra. Esta hipótese é corroborada pela crescente difusão das sociedades que surgem ali, com $12 \%$. Aliás, a evolução do capitalismo obrigou a que, grosso modo, a maquinofactura substituísse a manufactura, sendo neste contexto "a constituição de sociedades um fenómeno vulgar,46.

\section{O JURO}

Embora a documentação utilizada seja extremamente lacunar no respeitante ao juro, através dos dados obtidos conclui-se que as taxas praticadas, pelos particulares, variava entre os $5 \%$ e os $8 \%$, constituindo este 
último valor a moda do juro para os anos compreendidos entre 1928 e $1936^{47}$.

\section{AS QUITAÇÕES E O ENDIVIDAMENTO}

Sabendo que as quitações representam um crédito cedido e já reembolsado, total ou parcialmente, indicando-nos se os devedores, num determinado período, têm condições económicas para proceder ao pagamento da contraprestação, pode conhecer-se a partir destes dados um vector de uma dada economia, uma vez que o aumento de capital e da frequência das contraprestações obriga a um decréscimo do endividamento ${ }^{48}$ e vice-versa.

Tendo em consideração que a análise separada do crédito industrial, pela fraca representatividade na totalidade das operações, não permite a construção de uma linha evolutiva, decidimos observar a tendência do período através das operações de crédito onde um ou ambos os intervenientes pertencessem ao sector industrial ou comercial ${ }^{49}$.

\section{Gráfico II}

TOTAL ANUAL DAS QUITAÇÕES (1928-1936)

(EM ESCUDOS)

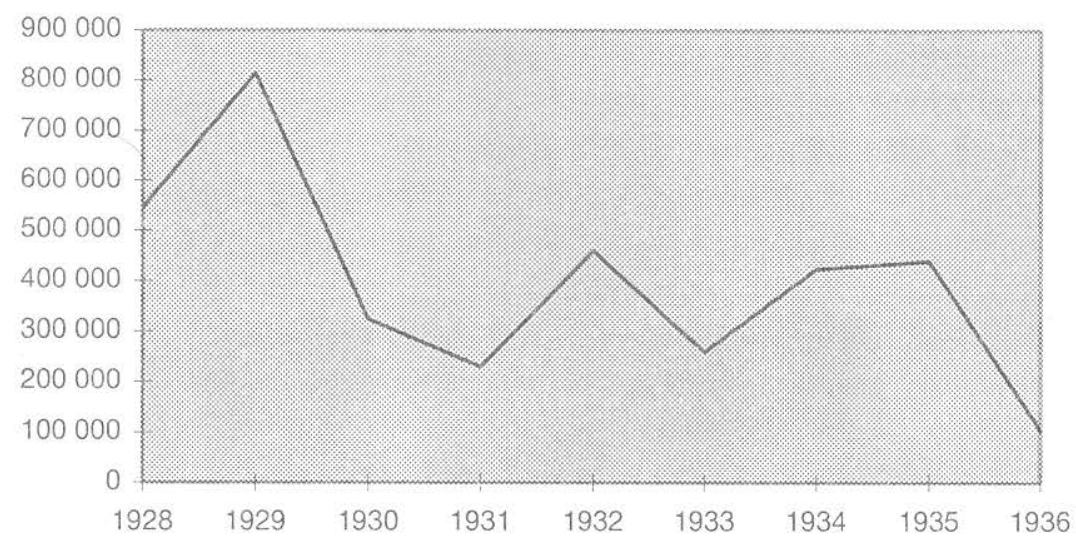

O gráfico II materializa as flutuações económicas caracterizadoras dos anos que medeiam entre 1928 e 1936. Concretizando: depois de, no ano de 
28 , o total anual das quitações se cifrar em $546000 \$ 00$, um valor um pouco acima da média deste período, logo no mítico ano de 29 , atinge o seu máximo, rondando os $900000 \$ 00$, para nos dois anos seguintes descer ao nível mais baixo. O ano de 1932 apresenta uma recuperação fabulosa (476 000\$00), conseguindo um aumento acima dos $100 \%$, relativamente ao ano transacto, voltando em 1934 a descer para os $261000 \$ 00$. Os três últimos anos parecem indiciar o início de um novo ciclo de crescimento: lento e gradual, mas seguro.

Em suma: salienta-se o facto de se poder dividir em dois ciclos o intervalo temporal em estudo. Por um lado, os anos de 1928 a 1933, verificando-se a turbulência dos valores, destacando-se o ano de 30 que, ao iniciar um período de baixa, faz pensar num primeiro impacte da Grande Depressão. Por outro lado, surge um segundo ciclo (1933-1936), indiciador de um regresso gradual à normalidade.

\section{CONCLUSÃO}

A estrutura empresarial conimbricense, entre os anos de 1928 e 1936, era constituída por uma heterogeneidade de actividades industriais e comerciais, o que atesta a vocação "ecléctica" da cidade, destacando-se, no entanto, o ramo ligado à alimentação e bebidas.

O próprio desenvolvimento da região acarretou a transformação das empresas que, gradualmente, adoptaram formas societárias mais modernas (tomando, sobretudo, a forma de sociedades por quotas), de molde a optimizar as suas respostas num mercado em crescimento. Contudo, este também sofria, cada vez mais, a concorrência de produtos de fora da região e do país, sendo, portanto, mais influenciável a partir do exterior.

Observa-se, assim, que os anos de 1929 e 1930, os quais se caracterizaram a nível mundial por um clima de crise, corresponderam a um período de alta no que diz respeito ao crescimento empresarial. Mas, logo de seguida, os ecos da depressão económica chegam a Coimbra, originando uma quebra brusca em 1931, mantendo-se a tendência de baixa até 1934. Os dois anos seguintes assinalaram uma tendência de melhoria e de regresso à bonança.

Aliás, o ano de 1934 já tinha sido marcado pelo aumento da média do capital social das novas sociedades, mas só os anos de 35 e de 36 conseguiram uma melhoria dos valores totais do capital social. $O$ que equivale a dizer que, em 1934, a relação capital/empresa era boa, mas o 
capital total aplicado foi fraco. Por seu turno, em 1935/36 os montantes aplicados no comércio e, mormente, na indústria foram dignos de realce.

Se o ano de 1929 foi caracterizado por um alto investimento, foi também marcado pelo pagamento das contraprestações, o que conduziu a que um volume anormal de capital regressasse às mãos dos credores. Isto parece indicar o relativo à vontade financeiro de comerciantes e industriais, bem como da população em geral.

Parece ser possível traçar uma linha de desenvolvimento que sofreu alterações neste período, atingindo um cume de prosperidade em 1929, uma quebra posterior e um gradual crescimento nos dois últimos anos em estudo. No entanto, o fim do período estudado anula a certeza desta última hipótese. Parece-me pertinente continuar, numa futura investigação, a pesquisar este tema, de molde a poderem tirar-se ilações mais seguras.

\section{NOTAS}

* O texto que ora se publica, acompanhado de um completo conjunto de gráficos e quadros, foi elaborado sob a orientação do Doutor José M. Amado Mendes e apresentado como tese de Seminário Científico-Pedagógico - Património Industrial: Investigação e Ensino - à Faculdade de Letras da Universidade de Coimbra (1997).

${ }^{1}$ Segundo a perspectiva de von Thünen citado por F. Braudel, Civilisation Matérielle et Capitalisme, vol. III, Paris, 1979, p. 26.

2 Irene Vaquinhas, "As relaçōes cidade-campo vistas a partir do crédito privado hipotecário: Coimbra e a sua região no terceiro quartel do século XIX", Separata das Actas del Colóquio de Metodologia Historica Aplicada, p. 31.

${ }^{3}$ Para tanto basta observar diversos números do Diário de Coimbra e atentar na diversa publicidade à cidade da Figueira da Foz e suas praias, aos seus hotéis, restaurantes e Casino Peninsular. Este caso teve particular relevância, por meados da década de trinta, aquando da organização de diversas excursões àquela cidade (muitas delas levadas a cabo pelo próprio jornal), com a participação de várias figuras proeminentes de ambas as cidades, bem como o exclusivo de numerosas páginas inteiramente dedicadas e até de alguns números especiais aquela cidade. Cfr., por exemplo, Diário de Coimbra, n. ${ }^{\circ} 1312$, de 29 de Maio de 1934, pp. 1, 3 e 4.

${ }^{4}$ Livros Notariais de Coimbra - 1928/1936. Arquivo da Universidade de Coimbra (A.U.C.).

${ }^{5}$ Michel Lacave, "Credit à la consommation et conjuncture économique: I'isle-envenaissin ( 1460-1560), Analles, E.S.C., ano 32, nº 6, Nov-Dez, 1977.

${ }^{6}$ Em estreita ligação com a panificação surge a agricultura e a moagem. Maria Raquel Moreira, A Moagem - Recolha Bibliográfica, "Cadernos de Arqueologia Industrial", Lisboa, 1989 , p. 5 . No que diz respeito a esta última actividade, não detectámos nenhuma constituição de sociedade. Todavia, registámos a falência de duas empresas. 
7 "As fábricas de massas são as mais consideradas no país, e as de bolachas nem confronto admitem", é com estas palavras que J. Cabral se refere a esta actividade na cidade de Coimbra. (Diário de Coimbra, n³52, de 25 de Maio de 1931, p. 1).

${ }^{8}$ José M. Amado Mendes - A área económica de Coimbra, Estrutura e desenvolvimento, Coimbra, Comissão de Coordenação da Região Centro, 1984. p. 183.

${ }^{9}$ José M. Amado Mendes, "Artes gráficas na Alta de Coimbra, Passado, Presente e Futuro", Alta de Coimbra, História, Arte, Tradição, $1^{\circ}$ Encontro sobre a Alta de Coimbra,Coimbra, 1988, p. 31.

${ }^{10}$ José M. Amado Mendes, A Área económica de Coimbra, pp. 96 e 106.

${ }^{11}$ Diário de Coimbra, ${ }^{\circ} 1299$, de 26 de Março de 1934, p. 1.

${ }^{12}$ Segundo a opinião de D. C. ( o nome não aparecia desdobrado no jornal). Diário de Coimbra, $\mathrm{n}^{\circ} 235$, de 20 de Janeiro de 1931, p. 4.

${ }^{13}$ Cfr. Fernanda Delgado Cravidão, "A Alta de Coimbra - que população?", Alta de Coimbra, História e Tradição, $1^{\circ}$ Encontro sobre a Alta de Coimbra, Coimbra, 1988, p. 102.

${ }^{14}$ Diário de Coimbra, n 2536, de 10 de Março de 1938, p. 1.

${ }^{15}$ Idem, no 1067 de 13 de Julho de 1933,p. 1.

${ }^{16}$ Idem, $\mathrm{n}^{\circ} 2473$, de 4 de Janeiro de 1938 , p. 3.

${ }_{18}^{17}$ Idem, $\mathrm{n}^{\circ} 218$, de 31 de Janeiro de 1931, p. 3.

${ }_{18}^{18}$ Idem, $\mathrm{n}^{\mathrm{O}} 222$, de 17 de Janeiro de 1931, p. 1.

${ }^{19} \mathrm{Idem}, \mathrm{n}^{\circ} 352$, de 24 de Maio de 1931 , p. 1.

${ }^{20}$ José M. Amado Mendes, "Cerâmica em Coimbra nos finais do séc. XIX e inícios do séc. XX. Achegas para o seu estudo.", A cerâmica em Coimbra, p.28, Comissão de Coordenação da Região Centro, Coimbra, 1982.

${ }^{21}$ José M. Amado Mendes, A Área económica de Coimbra, p. 323. O autor refere que as duas primeiras formas societárias foram criadas com o Código Comercial de 1867, ao passo que as duas seguintes foram criadas, respectivamente, em 1888 e 1901.

${ }^{22} \mathrm{Cfr}$. Gráficos, em apêndice, acerca do tipo jurídico das sociedades constituídas em Coimbra.

${ }^{23} \mathrm{Cfr}$. Gráficos, em apêndice, acerca do tipo jurídico das sociedades constituídas em Coimbra.

${ }^{24}$ O próprio Falcão Machado, em 1931, previa que se deixasse "passar a actual crise económica" e a indústria e comércio de Coimbra "singrarão, prósperos, florescentes, risonhos". (Diário de Coimbra, n ${ }^{\circ} 352$, de 24 de Maio de 1931, p. 1).

${ }^{25}$ Irene Vaquinhas e Fernando Fonseca Taveira, "Formas de investimento de capital: crédito privado e público em Coimbra no terceiro quartel do séc. XIX", p.101, Separata da Revista Portuguesa de História, t. XX, Coimbra, 1984.

${ }^{26}$ José Maria Amado Mendes, A Área económica de Coimbra,p. 340.

${ }^{27}$ Teixeira Ribeiro, Economia Política, 1962-1963, Coimbra, pp. 53, 55.

28 Irene Vaquinhas e Fernando Fonseca Taveira, Formas de investimento de capital, p. 100 .

${ }^{29}$ Teixeira Ribeiro, ibidem.

${ }^{30}$ José Maria Amado Mendes, ibidem, p. 341.

${ }^{31}$ Idem, ibidem, p. 342.

${ }^{32}$ Idem, ibidem, p. 341.

33 José Maria Amado Mendes, ibidem, p. 343. Quando nos referimos à área de Coimbra usamos a terminologia e a acepção do autor citado.

${ }^{34}$ Idem, ibidem,p. 343.

${ }^{35}$ Idem, ibidem, p. 344. 
${ }^{36}$ Irene Vaquinhas, "As relações campo-cidade vistas a partir do crédito privado hipotecário: Coimbra e a sua região no terceiro quartel do séc. XIX", p. 435, Separata das Actas del Coloquio de Metodologia Historica Aplicada.

${ }^{37}$ Conferir Quadro das quitaçōes, em apêndice. Este quadro apresenta todos os actos onde surjam como intervenientes indivíduos ou sociedades ligadas ao comércio ou indústria.

${ }^{38}$ Embora fosse pertinente analisar o crédito agrícola, no âmbito do nosso trabalho, sobretudo, devido às limitações das fontes utilizadas tal não foi possível.

39 José Maria Amado Mendes, A Área económica de Coimbra, p. 348.

${ }^{40}$ Idem, ibidem.

${ }^{41}$ Cfr. gráfico das categorias socioprofissionais dos credores, em apêndice.

${ }^{42}$ Porém, os alfaiates João Nunes e António dos Santos emprestaram, respectivamente: 22 mil escudos e 20 mil escudos, valores que, à época, eram notórios.

43 José M. Amado Mendes, A Área económica de Coimbra, p. 344.

${ }^{44}$ Ver Gráfico das categorias socioprofissionais dos devedores, em apêndice.

45 José Maria Amado Mendes, A Área económica de Coimbra, p. 348.

${ }^{46}$ José Maria Amado Mendes, A cerâmica em Coimbra, p. 28.

${ }^{47}$ Parecia ser moda o empréstimo de "pequenas e grandes quantias, a juro módico e com a maior prontidão e discrição", pelo menos a avaliar pela publicidade feita no jornal mais famoso da cidade (Diário de Coimbra, $\mathrm{n}^{\circ} 217,1$ de Janeiro de 1931).

${ }^{48}$ Evidentemente que tal conclusão só seria segura se, para o período em estudo, se possuíssem dados provenientes de todos os actos de contraç̧ão de dívidas, de modo a compará-los com os das quitações.

${ }^{49}$ Ver Quadro das quitações, em apêndice.

\section{FONTES MANUSCRITAS}

\section{Arquivo da Universidade de Coimbra ( A.U.C.)}

- $\quad$ Livros Notariais de Coimbra dos anos de 1928-1936.

\section{FONTES IMPRESSAS}

\section{Biblioteca Geral da Universidade de Coimbra}

- Diário de Coimbra dos anos de 1928-1936.

\section{BIBLIOGRAFIA}

BRAUDEL, Fernand, Civilisation Matérielle et Capitalisme, vol. III, Paris, 1979.

CRAVIDÃO, Fernanda Delgado, "A Alta de Coimbra - que população?", Alta de Coimbra, História e Tradição, $1^{\circ}$ Encontro sobre a Alta de Coimbra, Coimbra, 1988.

LACAVE, Michel, "Credit à la consommation et conjuncture économique: I'isle-envenaissin (1460-1560), Analles, E.S.C., ano 32, nº, Nov-Dez, 1977. 
MENDES, José M. Amado - A área económica de Coimbra, Estrutura e desenvolvimento industrial,1867-1927, Coimbra, Comissão de Coordenação da Região Centro, 1984.

MENDES, José M. Amado, "Artes gráficas na Alta de Coimbra, Passado, Presente e Futuro", Alta de Coimbra, História, Arte, Tradição, $1^{\circ}$ Encontro sobre a Alta de Coimbra, Coimbra, 1988.

MENDES, José M. Amado, "Cerâmica em Coimbra nos finais do séc. XIX e inícios do séc. XX. Achegas para o seu estudo.", A cerâmica em Coimbra, Comissão de Coordenação da Região Centro, Coimbra, 1982.

MOREIRA, Maria Raquel, A Moagem - Recolha Bibliográfica, Cadernos de Arqueologia Industrial, Lisboa, 1989.

RIBEIRO, Teixeira, Economia Política, 1962-1963, Coimbra, s.d..

VAQUINHAS, Irene e Taveira, Fernando Fonseca, "Formas de investimento de capital: crédito privado e público em Coimbra no terceiro quartel do séc. XIX", Separata da Revista Portuguesa de História, t. XX, Coimbra,1984.

VAQUINHAS, Irene, "As relações campo-cidade vistas a partir do crédito privado hipotecário: Coimbra e a sua região no terceiro quartel do séc. XIX", p. 435 , Separata das Actas del Coloquio de Metodologia Historica Aplicada. 